\title{
Letter
}

\section{Emoia impar (Squamata, Scincidae): not extinct in the Hawaiian Islands}

Although Fisher \& Ineich (2012) reported the extinction on Hawai'i of the common Pacific lizard Emoia impar (the azure-tailed skink) and indicated that no specimens have been collected on Moloka'i since the late 1800 s, unknown to them the skink was rediscovered in 2000 on the offshore islet of Mōkapu, Moloka ' $i$, where it has since been observed to have a stable population. Mōkapu islet is the most floristically rich offshore islet in the main Hawaiian Islands, with 34 native vascular plant taxa, and is also an important seabird nesting site. Rattus exulans was successfully eradicated from Mōkapu in 2008 when rodenticide pellets were aerially applied by helicopter.

A specimen representing the E. impar rediscovery (i.e. Wood \& Espaniola 12203 (BPMP 34625)) is deposited at the Bishop Museum, Honolulu, Hawai $i$, where both Robert Fisher and Allen Allison have confirmed its identification. Population estimates for E. impar have not been established on the 6-ha islet, yet the species is commonly observed by visiting researchers. Also present are the more common snake-eyed skink Cryptoblepharus poecilopleurus and the elusive mourning gecko Lepidodactylus lugubris.

Subsequent to the Fisher \& Ineich (op. cit.) publication in Oryx several news agencies (including USGS Newsroom, 2012; Scientific American, 2012; Science News, 2012) announced the extinction of E. impar in Hawai'i as the latest 'native' vertebrate species to become extirpated from the tropical archipelago. However, E. impar is not considered native, as there is still no published fossil evidence for lizards in Hawai 'i before humans arrived. Although Fisher \& Ineich cited James et al. (1987) as providing evidence of an early fossil lizard bone at Puu Naio, Maui, pre-dating humans in Hawai $\mathrm{i}$, this record was evidently misinterpreted by them. James et al. (op. cit.) actually rule out that interpretation, stating the single tiny lizard bone found in a prehuman sediment layer was 'clearly out of context'. This statement was meant to explain that the bone itself lacked the patina of the other bones in that layer, and the stratigraphy was susceptible to contamination from above. Subsequent excavations in that same layer (James \& Burney, 1997) yielded charcoal particles and a few pollen grains of two historically introduced plant genera (Myrica and Cupressus) in otherwise prehuman-aged sediment. It was concluded that some downward contamination by very small objects has probably occurred at the site, although dating of larger objects yielded consistently early to middle Holocene ages.

Emoia impar, along with two other species of skinks (Cryptoblepharus poecilopleurus, and Lipinia noctua) are considered to be 'canoe lizards' that arrived with the early Hawaiians during the Polynesian period. It is doubtful, based on the biogeography of other oceanic islands with varying degrees of isolation, that lizards could get to Hawai ' $i$ on their own. Instead, they fit the 'rafting profile' of creatures that typically reach less-isolated islands such as the Galapagos Archipelago, Mediterranean islands, some South Pacific islands, and Madagascar (e.g. rodents, lizards and tortoises). They can float to islands isolated by hundreds but not by thousands of kilometres.

An important point of the Fisher \& Ineich article (op. cit.) was that something, probably an invasive species of ant, caused a rapid and rangewide loss of E. impar in Hawai' $i$ c. 100 years ago, with the exception of the Na Pali Coast of Kaua ' $i$, where they persisted until the 1960s. The discovery on Mōkapu is significant as it possibly lacks the invasive ant species and served as a refugium for the skink. A careful study of the islet is warranted to determine how the species persists there whilst becoming extirpated elsewhere. The larger concern is that what happened on Hawai' $i$ 10o years ago could also happen in other Pacific Island archipelagos, many of which have highly endemic lizard faunas, and therefore understanding the mechanism should be a regional conservation priority.

KenNeth R. WOOD AND DAVID A. BuRneY, National Tropical Botanical Garden, Kalaheo, Hawai 'i, USA

E-mail kwood@ntbg.org

ALLEN ALLISON

Bernice P. Bishop Museum, Honolulu, Hawai'i, USA

ROBERT FISHER

U.S. Geological Survey, San Diego, California, USA

\section{References}

Fisher, R. \& Ineich, I. (2012) Cryptic extinction of a common Pacific lizard Emoia impar (Squamata, Scincidae) from the Hawaiian Islands. Oryx, 46, 187-195.

James, H.F. \& Burney, D.A. (1997) The diet and ecology of Hawaii's extinct flightless waterfowl: evidence from coprolites. Biological Journal of the Linnean Society, 62, 279-297.

James, H.F., Stafford, T.W., Steadman, D.W., Olson, S.L., Martin, P.S., Jull, A.J.T. \& McCoy, P.C. (1987) Radiocarbondates on bones of extinct birds from Hawaii. Proceedings of the National Academy of Sciences of the United States of America, 84, 2350-2354.

SCience News (2012) Another vertebrate species reported extinct from the Hawaiian Islands. Http://esciencenews.com/sources/science. daily/2012/03/31/another.vertebrate.species.reported.extinct. hawaiian.islands [accessed 29 May 2013].

SCientific American (2012) Blue-tailed skink declared extinct in Hawaii. Http://blogs.scientificamerican.com/extinctioncountdown/2012/03/21/blue-tailed-skink-declared-extinct-inhawaii/ [accessed 29 May 2013].

USGS Newsroom (2012) Another vertebrate species reported extinct from the Hawaiian Islands. Http://www.usgs.gov/newsroom/article. asp?ID=3145 [accessed 29 May 2013]. 